\title{
INTERPRETASI KARAKTER HEWAN DALAM FABEL: KAJIAN HERMENEUTIKA
}

\section{INTERPRETATION OF ANIMAL CHARACTERS IN FABEL: HERMENEUTICS STUDY}

\author{
Hasnawati Nasution \\ Kantor Bahasa Provinsi Lampung \\ Jalan Beringon 2 Nomor 40, Kompleks Gubernuran, Telukbetung, Bandar Lampung \\ Pos-el: ananasution2016@gmail.com
}

*)Naskah diterima: 9 Juli 2021; direvisi: 7 September 2021; disetujui: 15 Oktober 2021

\begin{abstract}
Abstrak
Fabel merupakan cerita yang diperankan oleh hewan, tetapi sifat dan tindakan yang dilakukan hewan tersebut adalah karakteristik manusia. Karakter manusia yang diperankan hewan tesebut dikaitkan dengan sifat hewan tersebut di alamnya. Penelitian ini bertujuan mengiterpretasikan karakter hewan dengan karakter manusia yang diperankannya di dalam fabel. Kajian interpretasi pada fabel ini menggunakan toeri hermeneutika Gadamer yang menggabungkan dialektis dan histori. Interpretasi yang dilakukan dikaitkan dengan karakter hewan yang dikenal masyarakat baik itu karakter fisik maupun karakter hewan secara metafornya, misalnya ular adalah hewan buas dan di dalam masyarakat sering digunakan sebagai metafor sifat licik. Berdasarkan analisis yang dilakukan dapat disimpulkan bahwa ada hubungan dan persamaan antara karakter hewan di dalam fabel dengan sifat manusia yang diperankannya. Hewan buas memerankan karakter manusia yang kuat dan berkuasa bahkan terkadang menyakiti hewan yang lemah. Hewan kecil seperti kancil memerankan sifat dan karakter manusia yang lemah, tetapi cerdik. Adakalanya sifat cerdik kancil dapat mengalahkan hewan yang kuat.
\end{abstract}

Kata kunci: interpretasi, karakter hewan, hermeneutika

\begin{abstract}
Fables are stories played by animals, but the nature and actions of the animals are human characteristics. The human character played by the animal is associated with the nature of the animal in nature. This study aims to interpret animal characters with the human characters they play in fables. The study of interpretation of this fable uses Gadamer's theory of hermeneutics which combines dialectics and history. The interpretation carried out is associated with animal characters that are known to the public, both physical characters and animal characters metaphorically, for example snakes are wild animals and are often used in society as a metaphor for cunning nature. Based on the analysis carried out, it can be concluded that there are relationships and similarities between the animal characters in the fable and the human traits they play. Wild animals portray human characters who are strong and powerful and sometimes even hurt weak animals. Small animals such as mouse deer portray the nature and character of humans who are weak, but clever. Sometimes the clever nature of the mouse deer can defeat a strong animal.
\end{abstract}

Keywords: interpretation, animal's character, hermeneutics 


\section{PENDAHULUAN}

Cerita rakyat berkembang di dalam masyarakat yang diwariskan secara turun-temurun dari mulut ke telinga. Cerita itu berkembang begitu saja dalam masyarakat tanpa diketahui siapa pengarang cerita itu. Banyak cerita yang memiliki alur dan tema yang sama di beberapa daerah, tetapi nama tokoh dan latar tempat terjadinya cerita menyesuaikan budaya daerah tempat berkembang cerita tersebut. Cerita rakyat merupakan salah satu sastra lisan yang berkembang di dalam masyarakat. Sastra lisan tidak hanya mengandung cerita, mitos, legenda, dan dongeng, tetapi juga mengandung berbagai hal yang menyangkut hidup dan kehidupan komunitas pemiliknya. Sastra lisan adalah identitas komunitas dan salah satu sumber penting dalam pembentukan karakter bangsa. Cerita rakyat yang berkembang di dalam masyarakat biasanya membawa pesan tertentu, misalnya kejujuran, menepati janji, akhlak pada orang tua, keberanian, dan ketulusan hati. Secara tidak langsung cerita ini memberikan pendidikan karakter pada anak-anak karena biasanya cerita ini diceritakan orang tua pada anak-anaknya. Cerita rakyat merupakan pintu masuk untuk memahami permasalahan masyarakat pemilik tradisi yang bersangkutan.

Cerita rakyat berkembang di dalam masyarakat yang diceritakan dari satu generasi ke generasi berikutnya secara turun-temurun. Oleh karena itu, banyak pakar sastra yang menyatakan bahwa cerita rakyat merupakan salah satu tradisi sastra lisan masyarakat. Tradisi lisan erat kaitannya dengan budaya dan adat istiadat yang melekat pada suatu masyarakat. Kebudayaan merupakan proyeksi pengetahuan dan aktivitas masyarakat terhadap persoalan kehidupan. Hasil kebudayaan itu kemudian menjadi pedoman bagi masyarakat untuk bersikap atau berperilaku dalam berinteraksi dengan anggota masyarakat pemilik kebudayaan tersebut. Pradopo (2000:4)

Berdasarkan penelitian terdahulu, kajian hermeneutik digunakan untuk menginterpretasikan sebuah cerita. Pada fabel, tokoh cerita adalah hewan. Untuk menginterpretasikan karakter hewan banyak peneliti menggunakan kajian hermeneutik. Beberapa kajian fabel yang menggunakan teori hermeneutik antara lain adalah sebagai berikut. Juanda, (2018) mengekplorasi nilai fabel sebagai sarana alternatif untuk pendidikan karakter siswa SMP. Kajian citra perempuan di dalam dongeng dengan analisis hermeneutik juga dilakukan oleh (Jetia, Juliana Mon (2020). Teori Hermeneutik digunakan sebagai teori dan metode memahami teks sastra sebagaimana ditulis oleh Anshari (2009) Teori hermeneutik digunakan sebagai landasan interpretasi terhadap sebuah karya sastra. Begitu juga halnya dalam menginterpretasikan karakter hewan di dalam fabel. Teori tersebut digunakan sebagai landasan untuk mendeskripsikan dan menginterpretasikan karakter hewan.

Masyarakat Lampung memiliki kekayaan kebudayaan salah satunya cerita rakyat. Lampung memiliki cerita rakyat tentang kepahlawanan, legenda, dan keajaiban yang diberikan dewa dan fabel. Cerita fabel yang berkembang di Lampung hampir sama dengan fabel yang berkembang di daerah lainnya di Indonesia. Hewan yang menjadi tokoh cerita antara lain harimau, gajah, ular, kancil, dan lain-lain. Hewan buas seperti harimau selalu digambarkan sebagai hewan yang suka menindas hewan lain. Harimau biasanya bergelar raja hutan. Tokoh kancil juga menjadi idola sebagai tokoh yang cerdik dan selalu memenangi keadaan.

Pada dasarnya, tokoh-tokoh dalam fabel merupakan manifetasi dari karakter manusia. Cerita di dalam fabel sama saja dengan cerita biasa, tetapi pada fabel tokohnya adalah hewan. Karakter hewan 
yang buas biasanya mewakili sifat kekuasaan dan kekuatan, sementara kancil mewakili karakter cerdik dan pintar.

Akan tetapi, untuk mengkaji sifat dan karakter hewan dalam fabel diperlukan interpretasi untuk menghasilkan sebuah kesimpulan. Interpretasi pada sebuah teks dapat dilakukan dengan menggunakan kajian hermeneutika Melalui kajian hermeneutik diinterpretasikan hubungan antara karakter hewan, ciri-ciri fisik dan hubungannya dengan hewan lain. Selain itu, faktor budaya juga menjadi landasan kajian hermeneutika ini. Hal ini menjadi alasan penulis tertarik meneliti karakter hewan pada fabel Lampung. Melalui penelitian ini, penulis mencoba mengkaji makna yang terkadung dalam fabel yang diambil dari cerita rakyat di Kecamatan Semaka, Kabupaten Tanggamus, dengan menggunakan kajian hermeneutika Gadamer. Adapun cerita rakyat yang akan dikaji pada penelitian ini adalah "Gong Maharaja." Dalam hal ini akan dikaji hubungan karakter dan ciri fisik hewan tersebut dengan karakter manusia yang diperankannya.

Hal yang menjadi permasalahan pada penelitian ini adalah mengetahui karakter tokoh hewan pada fabel "Gong Maharaja" dan hubungan karakter tokoh hewan tersebut dengan karakter manusia yang diperankannya.

Secara etimologis, kata hermeneutic berasal dari bahasa Yunani hermeneutin yang berarti menafsirkan kata benda hermeneia dan secara harfiah dapat diartikan sebagai penafsiran atau interpretasi (Sumaryono, 1999:23) Hermeneutika secara umum dapat diartikan sebagai suatu teori atau filsafat tentang interpretasi makna. Hermeneutika adalah studi pemahaman, khususnya pemahaman teks (Palmer, 2003:8)

Gadamer dalam Hadi (2004:90) menyatakan bahwa ada konsekuensi positif dan bermakna dari fenomenologi untuk mene- mukan problem filosofis pengembangan ontologi baru peristiwa pemahaman. Gadamer menginginkan untuk menggiring fenomena pemahaman yang lebih ditonjolkan. Gadamer bekerja pada tataran dasar dan pertanyaan fundamental: bagaimana pemahaman dapat berlaku, tidak hanya dalam hal-hal kemanusiaan, tetapi juga dalam pengalaman manusia secara keseluruhan. Gadamer sangat kritis terhadap ketergantungan pemahaman modern terhadap pemikiran teknologis yang berasal dari subjektivisme dalam menentukan kesadaran subjektif manusia dan kepastian nalar yang didasarkan kepada subjektifitas tersebut sangat bergantung pada poin referensi utama bagi pengetahuan manusia. Pemahaman mereka lebih dialektis yang mencoba memungkinkan pendekatan itu sendiri dibimbing oleh hakikat apa yang dipahami oleh keberadaan tersebut.

\section{LANDASAN TEORI}

Gadamer menguji pengalaman hermeneutisnya dengan mengkritisi konsep pengalaman. Dia menemukan konsep pengalaman yang ada terlalu berorientasi ke arah pengetahuan sebagai bentuk perasaan dan pengetahuan sebagai jasad data konseptual. Dalam kaitannya dengan cerita rakyat yang mengandung mitos-mitos yang berlaku di dalam masyarakat, Gadamer melontarkan konsep pengalaman historis dan dialektis dimana pengetahuan bukan hanya persepsi semata tetapi juga merupakan kejadian, peristiwa, dan perjumpaan (Gadamer, 2004:535)

Ketika seseorang mengatakan bahwa dia "milik" suatu kelompok sosial tertentu, maka ia menjadi milik suatu tempat tertentu di dalam sejarah dan negeri tertentu. Dia akan mengenal budaya, bahasa, adat, dan tradisi masyarakat tersebut. Dengan cara yang serupa dia akan menjadi pemilik bahasa dan sejarahnya karena dia berpar- 
tisipasi di dalamnya. Fenomena milik ini merupakan hal yang paling signifikan bagi pengalaman hermeneutis. Pengalaman tersebut merupakan landasan bagi adanya kemungkinan perjumpaan dengan warisan budaya seseorang di dalam teks. Teori pemahaman teks yang dikembangkan oleh Gadamer dikenal dengan istilah teori afektif historis (Faiz, 2002:20)

Gadamer merumuskan dua bentuk pemahaman, yaitu pemahaman terhadap konten kebenaran (truth content) dan pemahaman terhadap intensi (Palmer, 2003:213) Pemahaman terhadap konten berarti memahami makna yang dikandung proposisi dan substansi materi teks. Pemahaman terhadap intensi berarti memahami kondisi atau situasi dibalik fenomena atau teks. Pemahaman pada aspek kedua inilah yang kemudian menjadi perhatian Gadamer sebagai kesadaran pemahaman menyejarah.

Proposisi prasangka historikalitas berangkat dari pemikiran Heidegger tentang pemahaman yang berasal dari visualisasi dan imajinasi pemikiran. Gadamer mengistilahkan kerja prasangka subjek. Subjek dalam mengalisis pengalaman diberi kesempatan untuk melakukan prasangka atas sejarah teks. Kerja hermeneutika adalah kerja dialogisasi. Oleh karena itu, sejarah harus dibentuk sebagai objek dinamisasi melalui prasangka subjek (Bleicher, 2007:159). Prasangka subjek adalah pertanyaan awal atas objek sebagai proses pemahaman.

Fabel termasuk jenis teks cerita fiksi, bukan kisah tentang kehidupan nyata. Fabel sering juga disebut cerita moral karena pesan yang ada di dalam cerita fabel ber- kaitan erat dengan moral. Teks cerita fabel tidak hanya mengisahkan kehidupan binatang, tetapi juga mengisahkan kehidupan manusia dengan segala karakternya. Binatang-binatang yang ada pada cerita fabel memiliki karakter seperti manusia.

Nurgiyantoro, (2018:22) mengatakan cerita binatang seolah-olah tidak berbeda halnya dengan cerita yang lain, dalam arti cerita dengan tokoh manusia, selain bahwa cerita itu

menampilkan tokoh binatang. Cerita binatang juga hadir yaitu sebagai personifikasi manusia, baik itu yang menyangkut penokohan lengkap dengan karakternya maupun dalam persoalan hidup yang diungkapkan. Berdasarkan pendapat di atas, dapat disimpulkan bahwa cerita binatang tidak berbeda dengan cerita yang lainnya, dalam artian dengan tokoh manusia, selain cerita yang menampilkan tokoh binatang. Cerita binatang ini hadir yaitu sebagai personifikasi manusia, baik itu menyangkut sebuah penokohan dengan karakternya.

\section{METODE PENELITIAN}

Metode penelitian kajian hermeneutika menggunakan metode kualitatif, yakni dengan menginterpretasikan sebuah karya sastra menggunakan teori hermeneutika. Metode penelitian ini mengikuti alur kerja hermeneutik Gadamer sebagai kerja filsafat dan praktis. Ada enam alur kerja hermeneutika yang dikemukakan oleg gadamer yaitu, interpretator, teks interpretatif, historis teks, prasangka, analisa data, dan prasangka. (Darmaji, 1999:121)

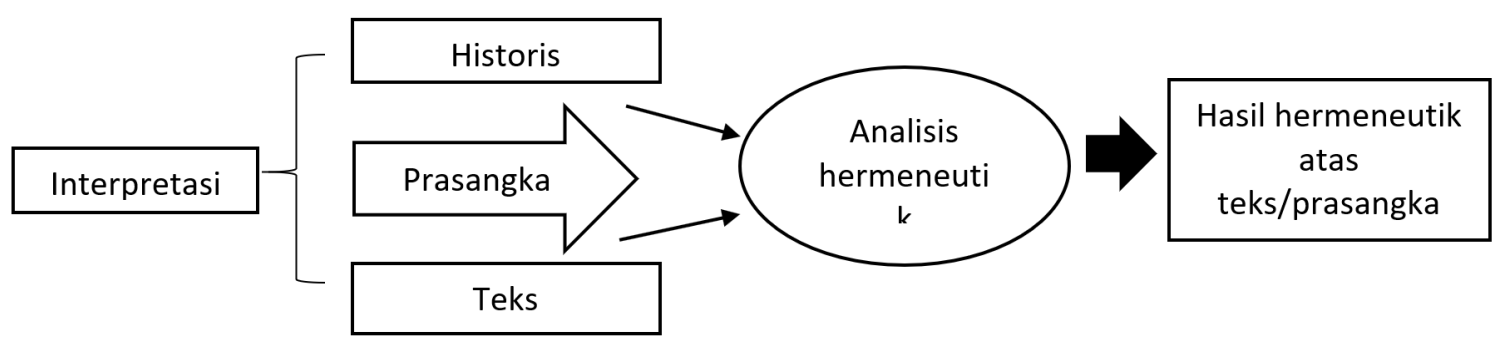


Darmaji mengutip Gadamer yang menjelaskan bahwa alur kerja hermeneutik Gadamer merupakan kerja interpretatif, bersifat dialogis yang melibatkan persoalan historisitas dan prasangka. Hermeneutika adalah sebuah konsep interpretatif terhadap simbol, tradisi, tindakan, teks, dan bentuk-bentuk material lainnya yang bersifat konkret, misalnya ilmu pengetahuan dan teknologi. Ilmu hermeneutika berdasarkan subjek dan objek. Subjek adalah interpretator sedangkan objek adalah sasaran interpretatif. Peran subjek terhadap objek adalah mendefinisikan apa yang dimaksudkan oleh objek. Pemahaman lebih menekankan pada struktur pengalaman. Struktur pengalaman merupakan usaha dialektik. Dialek pengalaman tidak hanya mengetahui, melainkan keterbukaan terhadap pengalaman yang dimainkan secara bebas oleh pengalaman sendiri. Pemahaman adalah historiskalitas, yaitu proses interpretasi produktif terhadap objek dengan memahami sejarah. Interpretasi tanpa pendekatan historis akan sangat sulit dalam memahami teks. (Bleicher, 2007:159)

Data penelitian ini adalah cerita rakyat dari Kecamatan Semaka, Kabupaten Tanggamus yang merupakan teks lisan. Data diperoleh langsung dari penutur asli. Metode yang digunakan untuk memperoleh data ini adalah metode rekam dan catat. Penutur bercerita dan peneliti merekam cerita tersebut. Cerita dituturkan dalam bahasa Lampung. Setelah itu, rekaman ditranskripsi dan diterjemahkan ke dalam bahasa Indonesia. Setelah data diperoleh, data diinterpresi secara hermeneutika dengan menggunakan alur kerja hermeneutik Gadamer.

\section{HASIL DAN PEMBAHASAN}

\section{a. Sinopsis Gong Maharaja}

Sekor gajah bernama Liman bersahabat dengan kancil. Gajah bertubuh tambun dan suka makan, sementara kancil bertubuh kancil dan bersifat cerdik serta licik. Suatu hari gajah melihat kancil menunggui sebuah benda besar yang tergantung di pohon. Bentuk benda itu seperti sebuah gong. Liman bertanya kepada kancil tentang benda itu. Kancil brerkata benda itu adalah gong maharaja. Ia ditugasi untuk menjaga gong tersebut. Meskipun kancil tahu bahwa benda itu adalah sarang lebah, dia mengatakan kepada Liman bahwa benda itu adalah gong milik rajanya. Hal itu membuat Liman penasaran dan ingin memukul gong tersebut. Kancil tidak serta merta mengizinkan Liman memukul gong. Kancil sengaja mengerjai Liman dan membuat Liman semakin penasaran. Kancil tahu bahwa Liman akan semakin penasaran jika keinginannya tidak dituruti. Akhirnya kancil mengatakan bahwa dia harus pergi jauh dulu sebelum Liman memukul gong agar raja tidak marah kepada kancil karena tidak menjaga gong milik raja. Akhirnya setelah kancil pergi, Liman memukul sarang lebah itu. Penghuni sarang langsung ke luar dan menyengat Liman karena merasa terganggu. Liman langsung berlari dan masuk ke sungai agar terhindar dari sengatan lebah. Liman kesal sekali karena menyadari bahwa kancil telah membohonginya.

\section{b. Interpretasi Teks}

Fabel merupakan cerita yang menggunakan binatang sebagai tokohnya. Namun, setiap binatang yang menjadi tokoh pada cerita tersebut mewakili sebuah sifat manusia, misalnya, ada binatang yang bersifat cerdik, jahat, dan sombong. Karakter binatang yang menjadi tokoh pada setiap cerita tentu memiliki ciri khas tertentu. Kancil sering menjadi tokoh yang cerdik yang bisa mengatasi masalahnya dengan kecerdikan akal yang dimilikinya. Hewan yang di dalam dongeng dikenal sebagai kancil sebenarnya adalah pelanduk, yakni 
hewan mamalia, berkaki empat yang bertubuh kecil dan memiliki bulu berwarna cokelat. Ukuran tubuh pelanduk tidaklah besar, tingginya hanya 50-an cm dan beratnya berkisar 1.6 sampai 2 kg. Kancil merupakan hewan herbivora, makanannya buah dan daun-daunan.

Tokoh kancil sangat banyak ditemui sebagai tokoh utama dalam dongeng (fabel) di nusantara. Hampir setiap daerah memiliki cerita yang menjadikan kancil sebagai tokoh utama. Pada umumnya, kancil dalam cerita rakyat nusantara digambarkan sebagai binatang yang bersifat positif, yakni cerdik dan pintar.

Bentuk fisik kancil secara hermeneutika dapat diinterpretasikan sebagai masyarakat biasa yang tidak memiliki kekuasaan dan kekuatan. Interpretasi lain dari kondisi kancil adalah orang yang lemah karena tubuhnya kecil. Dalam kehidupan nyata banyak kita manusia yang memiliki sifat seperti kancil. Tubuh kancil yang kecil menggambarkan bahwa orang yang berhasil atau orang yang panjang akal itu bukanlah melulu orang kaya atau orang yang punya kekuasaan. Tidak selamanya solusi sebuah masalah harus diselesaikan dengan kekuatan dan kekuasaan. Tubuh kecil kancil mewakili keadaan orang-orang dari kalangan biasa, masyarakat pada umumnya. Banyak masyarakat yang awalnya hanyalah orang biasa, tetapi karena kegigihannya dapat berhasil dan sukses dalam kehidupannya.

Sebaliknya, lawan kancil seringkali adalah hewan yang kuat, bertubuh besar, dan buas. Dapat diinterpretasikan bahwa hewan besar ini adalah orang yang kuat dan memiliki kekuasaan. Orang yang berkuasa biasanya dapat berbuat apa saja dengan kekuasannya. Apapun dapat diaturnya sesuai keiginannya karena dia memiliki kekuasaan. Tidak hanya kekuasaan, biasanya hewan buas dapat diinterpretasikan sebagai manusia yang bersifat jahat, kasar, dan uat.
Tidak hanya berkuasa dan kuat, interpretasi dari hewan-hewan yang menjadi lawan kancil ini juga menggambarkan orang yang memiliki kekayaan sehingga dia bisa berkuasa dengan kekayaan dan dimilikinya.

Interpretasi sifat manusia yang ada di dalam fabel bukanlah khayalan belaka. Sesuai dengan teori Gadamer, interpretasi yang dilakukan pada fabel nusantara melibatkan historisitas dan prasangka. Simbol hewan yang digunakan sebagai tokoh dalam cerita fabel tidak dapat terlepas dari budaya, tindakan, dan tradisi yang berkembang di dalam masyarakat. Interpretasi tesebut akan menghasilkan sebuah kesimpulan yang dikaji secara subjektif oleh interpreter.

\section{c. Historis dan Prasangka}

Dalam pemahaman prastruktur seseorang harus merujuk pada dirinya sendiri dan terhadap dunianya yang terbentuk secara historis. Pembentukan intensi-intensi dan prakonsepsi serta cara pandang seseorang merupakan warisan dari masa lalunya. Jadi seseorang bergerak dan menetap dalam suatu dunia pemahamannya yang terbentuk secara historis ketika karya sastra dipertemukan, ia akan menghadirkan dunia yang lain (Hadi, 2004:20)

Begitu juga halnya ketika seseorang membaca fabel. Binatang buas eperti harimau dan buaya telah dikenal sebagai binatang yang tidak bersahabat dengan manusia. Binatang buas ini dapat mencelakakan manusia. Oleh karena itu, di dalam fabel, binatang buas selalu dianalogikan sebagai hewan yang licik. Sementara binatang yang kecil seperti kancil atau hewan yang biasa dipelihara manusia dianalogikan sebagai hewan yang bersifat baik.

Pengalaman atau historis telah membentuk prasangka yang melekat dalam pola pikir manusia sehingga jika dalam sebuah fabel ada tokoh kancil atau sapi, pembaca 
telah berprasangka bahwa ini adalah tokoh baik. Jika ada tokoh ular dalam fabel, sebelum menyelesaikan membaca cerita, pembaca telah berprasangka bahwa ular adalah hewan yang licik.

\section{d. Analisis Tokoh Hewan dalam Fabel "Gong Maharaja"}

Analisis Tokoh Kancil

Berdasarkan cerita "Gong Maharaja" ditemukan dua tokoh yakni kancil dan gajah. Kancil memiliki sifat yang jahil tanpa memikirkan kerugian yang akan ditimbulkan sebagai akibat perbuatannya meskipun yang akan dirugikannya adalah temannya sendiri karena di dalam cerita ini dikisahkan kancil berteman dengan gajah. Pada cerita ini dikisahkan kancil mengetahui bahwa benda yang disebutnya sebagai gong adalah sebuah sarang lebah. Bila sarang lebah itu dipukul, tentulah lebah-lebah akan keluar dari sarangnya dan menyerang makhluk yang telah menganggu ketenangan mereka di dalam rumahnya. Sifat licik si kancil ini diinterpretasikan sebagai seseorang yang tega dan sengaja merugikan temannya. Orang seperti ini biasanya bertutur kata manis dan bermuka manis sehingga orang lain tidak akan mengira kalau dia akan melakukan hal yang jahat. Kancil yang memiliki badan kecil merupakan manifestasi seseorang yang biasa, mungkin juga tidak diperhitungakan akan melakukan sebuah kejahatan. Seringkali manusia terkecoh dengan penampilan yang baik dan ramah. Saat seseorang yang baik itu berusaha menjerumuskan dengan segala tipu daya, orang lain tidak akan menyadarinya tipu daya tersebut. Ketika kerugian atau musibah telah terjadi, barulah seseorang itu menyadari dia telah tertipu.

Dengan menggunakan kajian hermeneutika dapat diinterpretasikan bahwa sebuah kejahilan atau kebohongan itu memerlukan sebuah kecerdasan dan sikap yang manis. Kecerdasan diperlukan untuk menciptakan trik-trik kebohongan dan penipuan yang tidak disadari orang lain. Semakin tinggi tingkat kecerdasan seseorang, semakin halus penipuan dan kebohongan yang bisa dilakukan oleh seseorang. Secara historis asumsi ini dapat dibenarkan karena telah banyak terjadi selama kehidupan manusia. Bagi orang yang telah berpengalaman pernah kena tipu, tentu dia akan lebih berhati-hati terhadap orang yang bermulut manis. Prasangka akan lahir berdasarkan pengalaman atau historis.

\section{Analisis Tokoh Gajah}

Pada cerita "Gong Maharaja" gajah digambarkan sebagai hewan yang lugu sehingga dapat tertipu oleh kancil. Gajah terkecoh oleh kata-kata kancil yang menyatakan bahwa kancil sedang menjaga sebuah gong milik raja. Dapat diinterpretasikan bahwa gajah berpikir jika gong tersebut milik seorang raja, tentulah gong itu sangat bagus, mahal, dan suara gong itu bagus. Melalui alur kerja hermeneutika Gadamer, sifat yang dimilki oleh gajah ini dapat ditelaah berdasarkan historisitas dan pengalaman. Berasarkan sejarah dapat dibuktikan bahwa barang-barang peninggalan yang dimiliki oleh raja atau bangsawan zaman dulu adalah barang-barang yang berkualitas bagus. Benda-benda seperti gong, alat rumah tangga, dan senjata peninggalan sejarah terbuat dari logam berharga, misalnya gong dan gelas yang terbuat dari emas. Berdasarkan pengalaman ini, tidak salah jika gajah mengira bahwa gong raja yang dijaga oleh kancil adalah benda istimewa. Keyakinan itu mendorongnya untuk mencoba memukul gong tersebut.

Gajah merupakan manifestasi sifat manusia yang tidak mampu mencermati keadaan lingkungan. Dia tidak memeriksa terlebih dahulu benda yang disebut kancil sebagai gong. Agar seseorang tidak terjeru- 
mus ke dalam hal-hal yang merugikan dirinya, dia harus mampu mencermati keadaan lingkungannya. Seharusnya gajah tahu bahwa dia dibohongi kancil jika dia melihat dulu benda yang disebut kancil sebagai gong itu. Situasi ini dapat diinterpretasikan bahwa kita harus melakukan sesuatu dengan penuh ketelitian agar tidak terjebak dalam tipu daya seseorang. Jika seseorang hanya mengikuti keinginan hatinya atau nafsunya, dia akan terjerumus kepada halhal yang merugikan dirinya. Kesimpulan ini tentu diperoleh dari pengalaman dan hitoris kehidupan manusia. Hal ini sejalan dengan teori Gadamer yang menyatakan bahwa historis akan menimbulkan prasangka dan menghasilkan interpretasi.

\section{e. Legitimasi}

Interpretasi yang dilakukan dengan menggunakan teori Gadamer membantu pembaca untuk membuktikan bahwa interpretasi dan prasangkanya terhadap sebuah materi sastra sesuai dengan hitoris atau pengalaman yang telah diperoleh dalm hidup. Penerapan kajian hermeneutika dalam membaca fabel membuat pembaca mengerti berbagai karakteristik manusia meskipun diperankan oleh hewan. Analogi karakteristik hewan buas dan jinak memudahkan pembaca memahami fabel. Hewan yang buas akan menjadi analogi sifat-sifat yang buruk dan hewan jinak akan menganalogikan sifat yang baik.

\section{PENUTUP}

Cerita rakyat merupakan salah satu karya sastra lisan yang harus dilestarikan. Salah satu bentuk cerita rakyat adalah dongeng fabel. Setiap tokoh hewan yang ada di dalam cerita akan mewakili satu sifat manusia. Cerita fabel biasanya mengandung pesan moral dan unsur budaya yang sangat kental. Melalui kajian hermeneutika, pesan yang terdapat di dalam cerita dapat diinterpretasi lebih rinci. Tokoh kancil yang kecil diinterpretasikan sebagai masyarakat biasa yang tidak memiliki kekuasaan dan kekayaan tetapi memiliki banyak akal agar keinginannya tercapai. Hewan kuat dan buas seperti gajah, singa, dan buaya merupakan manifestasi dari sifat manusia yang punya kekuasaan, kekuatan, dan kesombongan. Selain itu, cerita rakyat juga akan membantu pembaca mengenal budayanya karena cerita rakyat memiliki berbagai macam simbol yang berkaitan erat dengan budaya.

\section{DAFTAR PUSTAKA}

Anshari. (2009). Hermeneutika sebagai Teori dan Metode Interpretasi Makna Teks Sastra. Sawerigading, Vol 15 No., 187-192.

Bleicher, J. (2007). Hermeneutika Kontemporer, Hermeneutika Sebagai Metode, Filsafat, dan Kritik. Fajar Pustaka.

Darmaji, A. (1999). Pergeseran hermeneutik ontologis melalui bahasa dalam pemikiran Hans-Georg Gadamer. Penerbit Universitas Indonesia (UI Press).

Faiz, F. (2002). Hermeneutika Qur'ani : Antara Teks, Konteks dan Kontekstualisasi. Qalam. http://opac.ut.ac.id/detail-opac?id=16211.

Gadamer, H.-G. (2004). Kebenaran dan Metode: Pengantar Filsafat Hermeneutika. Pustaka Pelajar.

Hadi, A. W. M. (2004). Hemeneutika, Estetika, dan Relegiuitas. Matahari.

Jetia, Juliana Mon, A. N. (2020). Citra Perempuan Dalam Dongeng-Dongeng Daerah NTT. Jurnal Pustaka, Vol XX No., 10-21.

Juanda. (2018). Ekplorasi Nilai Fabel sebagai Sarana Alternatif Edukasi Siswa. Jurnal Pendidikan Bahasa Dan Sastra, 
Vol. 18 No, 294-303. https://doi.org/ Pradopo, R. D. (2000). Pengkajian Puisi. Gaddoi:10.17509 jah mada University Press.

Nurgiyantoro, B. (2018). Teori Pengkajian Sumaryono, E. (1999). Hermenuetik Sebuah Fiksi. Gadjah Mada University Press.

Palmer, R. E. (2003). Hermeneutika; Teori Baru Metode Filsafat (Edisi Revi). Kanisius. Mengenai Interpretasi. Pustaka Pelajar. 